\title{
Complexity Arising from "Escape Room" Style Activities in A High School Calculus Class
}

\author{
Dave Carlgren ${ }^{1 \star}$ (1), Aaron Schultz ${ }^{1}$ (])
}

${ }^{1}$ Maple Leaf International School - Wuhan, CHINA

*Corresponding Author: davidcarlgren@mapleleafedu.com

Citation: Carlgren, D., \& Schultz, A. (2022). Complexity Arising from "Escape Room" Style Activities in A High School Calculus Class. Contemporary Mathematics and Science Education, 3(1), ep22003. https://doi.org/10.30935/conmaths /11560

\begin{abstract}
Traditional mathematics instruction serves many purposes in today's education systems. Providing step-by-step guidance and lecture-style tuition in mathematics is often the norm. However, emerging insights into challenge, grit, and optimal teaching and learning strategies suggest that there may be benefit from increasing the mental burden on students. A short-term investigation was conducted into the use of choice, unstructured assessment and a "locked box" style of student-directed task for a high school calculus class of ESL students in China. Results were encouraging and suggested the emergence of a complex learning system composed of individual students that transcended the typical classroom experience.
\end{abstract}

Keywords: calculus, complexity, emergence, puzzle-based, play-based, competition, collaboration, cooperation Received: 10 Nov. $2021 \bullet$ Accepted: 6 Jan. 2022

\section{INTRODUCTION}

There is copious literature about the benefits of play puzzles, and games in mathematics instruction and practice (Palm, 2009; Palm \& Burman, 2004; De Lange, 1996; Ernest, 2002). Much of this research focuses on the areas of engagement and uses university undergraduate students as the primary subjects of inquiry. At the high school level, however, there appears to be little done with regards to play, puzzle and games-based assessment, evaluation, and research comparatively. However, it has been acknowledged by Thomas et al. (2013) that a good characteristic of puzzles is that they cannot be solved by rote, rather they are invaluable at making students think. Similarly, Klymchuk (2017) states that "[s]olving puzzles can be linked to the development of professional skills." (p. 2). The combination of these two factors, not by rote and as preparation, were a motivating factor for this study. Building on Schoenfeld's (1985) work where he found that university students tend to spend a small amount of time on planning solutions but rather quickly jump into 'doing mathematics' and writing it down. Selden et al. (2000) when investigating university calculus students' non-routine problem-solving methods, found that above-average students often used sophisticated methods that led them nowhere instead of accessing known calculus methods and knowledge. Even worse, perhaps, was that the failure rate of students increased when students in another study were asked to solve calculus problems that had a non-routine wording (Klymchuk, 2017). These factors combined to create the concept of using a student-created and solved escape room model for review of a high school calculus course. The primary question was: What observable impacts could be noted when students are provided with the opportunity to engage in an open-ended play-based opportunity in a high school calculus class?

\section{THEORETICAL CONSIDERATIONS AND METHODOLOGY}

In this study, an open concept model for the project was used. Building on the concept of "enabling constraints" championed by Davis et al. (2015), enough information was provided to students to fuel their desire and energize them for the opportunity to attempt to stump each other. Rather than a purely competitive environment, as recommended by Plass et al. (2013), a combination of collaboration and competition was considered to be optimal for student engagement and learning. Collaboration, as reported by Slavin (1988), is the most effective when group members have a shared group goal that is important, and the success of the activity is dependent on all members of the group - each member must be accountable. Further, Mullins et al. (2011) found that collaboration improved performance on both conceptual and procedural tasks but only when students still tended to perform the procedural tasks with inefficiency and inaccuracies. However, Fu et al. (2009) found that both collaborative and competitive features increased enjoyment in learning. In addition, when competitive features were present and stressed, students demonstrated an improvement in analytical skills and separated concepts into parts as a means to better comprehend the organizational structure. As reported in Klymchuk (2017), the collaborative features encouraged higher level synthesis learning from information and, therefore, higher level learning. 
The environment for this exploration involved several coinciding factors that made it particularly pertinent. One of these was that the school in China was an offshore school with a North American curriculum. This is relevant for a few reasons; it makes the findings more potentially applicable to a North American audience as the curriculum material is comparable; the school regularly undergoes inspections, and in this particular year was applying a Cognia (an international educational-practice certifying body) process of observation and evaluation as the external criteria for certification meaning there were trained "observers" in the school; and finally, the end of the COVID-19 isolation procedures in China meant that these particular students were returning to regular classes, in which their predominant expectation is to be provided with lectures and highly structured lessons. The methodology was largely motivated by the presence of trained Cognia observers who were present solely to collect information on classroom and student activities during a variety of lessons. As such, an independent observer was present in the classroom to collect data without prior awareness of, or involvement in, the class or the project.

It is important to note that this study was not conducted as an action research project, nor with the intent of being scientific. Rather, following an Educational Design Research (EDR) methodology, including the opportunity for iterative improvements to be made, for emergent phenomena to occur, for feedback through the system and indeterminate conclusions to occur, there was a notably different intent. Science, traditionally, seeks truth. EDR, as a complexivist methodology, seeks meaning in context and allows for diverse interpretations to emerge.

\section{Key Questions}

If a group of students who expect lecture presentation are provided with a "locked box" independent learning opportunity, how will they respond to it? What will change in the classroom environment? What will an independent evaluator note about the interactions among and between students, about the learning environment and the depth of learning opportunities? All of these questions were formed prior to the action taken in the class.

\section{The Project}

Students were provided with the opportunity to engage in a playful act of creating and sharing an escape room (locked box) style activity. Working in groups of varying numbers, they were to design a set of tasks that would eventually lead to a solution that would reveal a "way out." The rest of the project was intentionally left open for student experimentation and interpretation. Assessment and evaluation of the project was also left up to the groups to determine for themselves and sets of criteria were suggested but not required (for example, peer evaluation, teacher rubric assessment, survey, student completion rate, submission of sample problems, etc.). The project was introduced prior to the end of the course and was intended as a review of course material. Three groups were formed varying in number from 3 students to 14 students. All students were required to submit a form that outlined their specific roles within the group prior to the creation of any problems. They were all then asked to determine how much time would be required for completion of the project and to "play" the game. This time was allocated during traditional review time in the final week of the course.

\section{The Observer}

To authenticate an observer, there is a protocol involving training and calibration that is followed. The training, because of the pandemic, took place in an online course comprised of modules that focused on each of the areas of observation and inquiry. Once the modules were completed, a mock observation was conducted involving a video of a classroom experience. The calibration and authentication component was completed by having the observer rate the video lesson accurately compared to the standard set forth by Cognia. This method, while perhaps not ideal, lends a level of validity to the use of the tool and to the observer in this instance. Additionally, the observer has had experience with more than 20 individual and independent observations, many of which have been further calibrated with other observers also present in the same classroom and have all been reliably at the expected level.

The ELEOT tool is part of AdvancEd, an organization built on their psychometric analyses. As reported on the ELEOT website (AdvancEd, 2021) regarding validity and reliability, "to date, data collected from over 45,000 classroom observations has established the overall reliability and validity of ELEOT related to test content, response processing and construct validity" (p. 6). Additionally, "The overall reliability of the measure is .94 using a Cronbach's alpha, which is considered a very strong level of reliability. To assess construct validity, a confirmatory factor analysis of the measure revealed the root mean square error of approximation (RMSEA) as .068 indicating an adequate fit of the model to the data" (AdvancEd, p. 6).

The independent observer has written the following about his classroom observations, role, and training to provide further context:

"As a certified Cognia ELEOT 2.0 observer, I have been trained to observe classroom environments. The training I have received observes and investigates the learning environment that students are immersed in classrooms. It is specific to the environment, and while it is certainly true that the teacher is part of and affects that environment, the ELEOT 2.0 is not a teacher observation tool. It is not a tool used to evaluate teachers or their practices, but rather it is a tool used to document various aspects of the learning environment. More specifically, the ELEOT tool evaluates how student-centered and conducive to learning an environment is. Of course, this encompasses what many would readily think regarding the learning aspects of a classroom including coursework, activities, discussions, technology, and feedback, but also it evaluates other aspects of the environment as well such as equitability, expectations, support, community, and respect. And certainly, these observations are not restricted to be between teachers and students, but also include collaborations amongst students, and everyone's interactions with the physical environment around them as well. Additionally, the observations are made not solely by observing, but also through conversations with students. Observations are recorded on a rubric that is divided into seven categories including Equitable Learning Environment, High Expectations Environment, Supportive Learning Environment, Active Learning Environment, Progress Monitoring and Feedback Environment, Well-Managed Learning Environment, and Digital Learning Environment. Each of these categories are further divided into 3 or 4 detailed 
aspects of each category. It is each of these aspects that are then scored on a scale of $1-4.4$ is rated Very Evident, 3 is Evident, 2 is somewhat Evident, and 1 is Not Observed. In the process of Cognia Accreditation, dozens to possibly hundreds, depending on school-size, of observations are made and documented of all classes offered by the school to get a picture of the typical classroom environment throughout the entire school. They are just one piece of the evidence used to conclude the overall school environment. So, in short, the ELEOT 2.0 tool is used to help identify and document observable evidence of classroom environments that are conducive to student learning.

Recently, I made three separate observations of same Calculus class. They happened on three consecutive school days. The classes I observed were focused on review for their upcoming semester final exam. During these classes different groups of students were leading the class in games that they had created for review for their exam. Prior to the observations, I was not detailed on what specifically would be happening in the class, the requirements of the assignment, nor how it would be marked (if at all), but merely was informed that students would be leading games for review.

After observing the class for three days and watching 3 different groups present their games and conversing with several members of each group, I had one unanswered question that I never found a satisfactory answer to. Why did students choose to create games that were so ambitious?

Part of the ELEOT observations require observers to converse with students about expectations and feedback - could students explain how their work would be assessed. In my conversations with students, all of them said that their work would be assessed on rubrics that they created for their own games. The teacher would use the rubric and give them a mark and their peers would also use the rubric and give them a mark as well. So, if students are creating their own rubrics for their games, then it couldn't be that their teacher is forcing them to tackle such ambitious games in pursuit of high marks.

Another part of the ELEOT observations investigates how learners take responsibility for and are self-directed in their learning. Well, maybe it was the requirements of the assignment caused students to create such complicated and elaborate games for review. Yet in my observations, students told me that the only requirements they were given for the assignment was to make a game and make it interesting. One group even went so far as to say that they worked every day after school for a month to prepare and create their game. From student conversations and class observations, it certainly wasn't the requirements of the assignment itself that caused students to make such extravagant games. Although one student did offer one insightful comment regarding working on the game. He said that "more people led to more power" explaining that they held each other accountable in their group for accomplishing individual parts of the game. And later, further explaining that when everyone had completed their individual tasks, together they "enjoyed the group cooperation and sense of accomplishment it gave them."

Observations made using the ELEOT 2.0 tool, didn't offer any more insight into the motivations behind student productivity. And so, my question of the reason of such great student ambition won't be answered by ELEOT. However, because it was clear that students were motivated, other aspects from the ELEOT tool certainly were highlighted. One of the categories of ELEOT is high expectations environment. Although students weren't able to explain to me why they had such high expectations, it was clear that students had high expectations for themselves. The games they created certainly were intricate and involved. The products they presented demonstrated higher order thinking skills to create them, and even required them of those playing the games. One game even required independent research on the Internet in the search for clues. Certainly, students held themselves to a higher standard than a traditional Jeopardy-like game or a contest of who can answer faster. By the nature of the games that students created they also certainly created an environment for their peers that was supportive and active, two other categories included in the ELEOT tool. Students created games that required their peers to work in teams, creating a sense of community and rivalry, And within each team, students were clearly engaged, working together to accomplish tasks, and were not afraid of any negativity resulting from their efforts.

Through the lens of the ELEOT tool, and as a teacher myself, I was also drawn to the category of Progress Monitoring and Feedback Environment. As a teacher, I am continually fighting the battle of marking student work and trying to give timely, useful feedback. Students through their games had created their own systems for this, that required no marking or feedback from their teacher. Through systems of getting hints, rewards and punishments, progression through the game, and even competition with other groups, each game had created their own unique mechanism for giving students feedback, and most impressively students were able to use these mechanisms on their own or within their team without the need for feedback directly from the teacher. They were monitoring their own learning, and able to self-correct and make adjustments as needed, not only to make progress in the game, but by doing so also further and deepen their learning of the underlying calculus they were reviewing.

These review games provided an opportunity to see and document a classroom environment that was clearly studentcentered and conducive to student learning. Nearly all categories earned Very Evident ratings, but one category the Digital Learning Environment, received mixed results. This was simply because it completely depended on the requirements created by each game. One group had decided to restrict the use of technology for their game. However, another group clearly encouraged it by requiring independent research on the Internet. But regardless, overall, these classes that I observed scored high, "Very Evident", on the ELEOT observation tool, and demonstrated a student-centered environment conducive to learning. Conversely, however, 
Table 1. Accumulated data scores

\begin{tabular}{|c|c|c|c|c|c|}
\hline & Day 1 & Day 2 & Day 3 & Averages & Percentage \\
\hline Equitable learning environment (16) & 14 & 14.5 & 14.5 & 14.3 & 90 \\
\hline High expectations environment (20) & 20 & 13.5 & 19.5 & 17.7 & 88 \\
\hline Supportive learning environment (16) & 13.5 & 16 & 16 & 15.2 & 95 \\
\hline Active learning environment (16) & 13.5 & 16 & 15 & 14.8 & 93 \\
\hline Progress monitoring and feedback environment (16) & 14 & 15 & 15.5 & 14.8 & 93 \\
\hline Well-managed learning environment (16) & 13 & 15.5 & 15 & 14.5 & 91 \\
\hline Digital learning environment (12) & 8 & 3 & 10 & 7.0 & 58 \\
\hline
\end{tabular}

during a debrief after each class, which was led by the classroom teacher, students didn't always have a similar high opinion of the games they had just played. When discussing the value of review activities such as these, several students questioned their efficiency compared to a traditional review - one in which students simply worked through papers with question after question on them. In fact, some students said they would even prefer this traditional method, despite readily agreeing that these games were more fun, engaging, and active than a traditional review. It's an intriguing mindset of these students that is worthy of further investigation, but despite this differing opinion it cannot be denied that in this classroom, during my observations, students were provided an environment that was equitable, supportive, active, engaged, well-managed, and had high expectations with mechanisms for progress monitoring and feedback."

\section{RESULTS}

It is clear from the Observers' observations that students were the primary focus of the classroom dynamic through these activities. In addition, the aspect of student engagement and feedback were enhanced, much to The Observer's surprise and expressed awe. His notes and comments along with the original ELEOT tool are provided as Appendix A-D, respectively.

A summary of the scores, average scores and percentages is provided in Table 1. In parentheses are the total available scores for each learning environment descriptor. While the averages and percentages may seem to be trivial statistics, they demonstrate that many of the environmental factors being observed and related to the research questions. Students consistently created and interacted within an environment that was equitable, had high expectations, in this case self-imposed, was active, rich with feedback, and was well-managed. It can also be noted that the digital learning was differentiated by groups, as not all groups took advantage of digital media to present and engage the class with their tasks.

Returning to the initial questions:

If a group of students who expect lecture presentation are provided with a "locked box" independent learning opportunity, how will they respond to it?

According to the notes that the Observer made, students in this class appeared to embrace the challenge, competition, and cooperative aspects of the project. It enabled them to interact with each other and with the course material in new ways than the "typical" class review. As the Observer wrote, "students held themselves to a higher standard than a traditional Jeopardy-like game or a contest of who can answer faster.
By the nature of the games that students created they also certainly created an environment for their peers that was supportive and active." Additionally, the data also points to this finding as scores for active and supportive are amongst the highest. This finding is also consistent with those described in Klymchuk (2017) and Plass et al. (2013). The authors attribute this primarily to the complex interplay of collaborative environment, inherent competition and a level of challenge that was determined by the students themselves, though no empirical evidence is provided in this study to support this conjecture.

\section{What will change in the classroom environment?}

The classroom environment appeared to exhibit two emergent characteristics in this complex learning environment. As documented by the Observer, one was the high level of expectations, as mentioned earlier, while a second may be related to feedback. As the Observer writes,

"Through systems of getting hints, rewards and punishments, progression through the game, and even competition with other groups, each game had created their own unique mechanism for giving students feedback, and most impressively students were able to use these mechanisms on their own or within their team without the need for feedback directly from the teacher. They were monitoring their own learning, and able to self-correct and make adjustments as needed, not only to make progress in the game, but by doing so also further and deepen their learning of the underlying calculus they were reviewing."

In short, students in this class and with this project demonstrated the abilities to create a level of expectation that demanded rigour while also self-regulating and self-correcting that level of expectation through feedback loops. These are also prescriptive elements of complex learning environments, also known as learning systems.

One caveat at this point is germane. Because the Observer was present for only these limited interactions, he was not privy to much of the work of establishing class routines, building individual self-esteem and expectations, and developing feedback cycles within the regular class practices. As the classroom teacher for this group, I can attest to the fact that I contributed to each of these but was also pleasantly surprised by the high level of emergent behavior during the escape room project.

What will an independent evaluator note about the interactions among and between students, about the learning environment and the depth of learning opportunities?

Based on his noted and written reflections, this independent observer was intrigued, positively surprised, and impressed by the level 
of difficulty of the problems, by the support structures that students self-generated, and by the interactions between students. It is also worthy of note that students did not share the same thoughts about the project as they were not sure that it provided the same level or depth of experience that they anticipated, or thought was required. As the Observer has written, the concept of student self-perception of an activity and its benefits may be beyond their capacity to comprehend as they are inherently embedded within the topic itself (it is their subject of interest, not yet objectified) and is an area for potential future examination.

What observable impacts could be noted when students are provided with the opportunity to engage in an open-ended play-based opportunity in a high school calculus class?

In short, students in this school, and environmental situation, created a complex learning environment that exhibited many aspects of self-regulation, continuous change, feedback cycles to control and monitor growth and change, challenge, equity, engagement, and support.

\section{DISCUSSION}

Complex systems are difficult to define empirically but tend to exhibit sets of characteristic behaviors regardless of the type or scale. According to Cilliers (1998) these include:

- Many elements,

- Interactions that involve information,

- Rich interactions,

- Non-linearity,

- Short-range interactions (moderated influence),

- Loops of interaction (feedback),

- Openness to environmental conditions and feedback,

- Lack of equilibrium (constant change),

- History, and

- Elements each have an embedded view of their role without vision of the whole.

While this is not an exhaustive list, these elements are clearly represented in The Observer's evaluation and the answers to the initial research questions. Further to Cilliers (1998) components is the assertion that developments of these structures "can also be called learning" (p. 17). Fundamentally this was the purpose of the project student learning. It appears that what has been cocreated by the teacher and the students through engagement in this escape room project is a complex learning environment - a group organization without central control that learns and adapts. The implication of this is that the class itself is acting as a learning organism, not just the individual students. This speaks directly to the final characteristic of Cilliers' (1998) list as well as the observation that The Observer made about students not believing that their actions were as beneficial as "traditional" review might have been. Perhaps, as a learning system with students as components, they are not able to be aware of the functioning of the entire system because they are immersed in action at their own individual level. The collaborative/competitive combination may be partially responsible for this emergent phenomenon, which is an area for further investigation. Regardless, it appears clear that a complex learning system was created within the microcosm of this calculus classroom.

In the view of the authors, one is left to ponder what implications this might have for future learning, group work, interactivity among students, testing practices, and learning theory as we move inexorably toward greater need for higher level actions and thinking skills in students at all levels.

Author contributions: All authors were involved in concept, design, collection of data, interpretation, writing, and critically revising the article. All authors approve final version of the article.

Funding: The authors received no financial support for the research and/or authorship of this article.

Acknowledgements: We would like to acknowledge the efforts of all the teachers and students at the participating school for their tireless efforts throughout the coronavirus difficulties. For those on campus and away, these were challenging times.

Declaration of interest: Authors declare no competing interest.

Data availability: Data generated or analysed during this study are available from the authors on request.

\section{REFERENCES}

AdvancEd. (2021). Frequently asked questions index. https://www.advanc-ed.org/sites/default/files/mobile_apps/ eleot/eleot_faqs.pdf

Cilliers, P. (1998). Complexity and postmodernism: Understanding complex systems. Routledge.

Davis, B., Sumara, D, \& Luce-Kapler, R. (2015). Engaging minds: Cultures of education and practices of teaching. Routledge. https://doi.org/ 10.4324/9781315695891

De Lange, J. (1996). Using and applying mathematics in education. In A. C. Bishop (Ed.), International handbook of mathematics education (pp. 49-97). Kluwer Academic Publisher. https://doi.org/ 10.1007/978-94-009-1465-0_4

Ernest, P. (2002). Empowerment in mathematics education. Philosophy of Mathematisc Education Journal, 15, 1-16. https://doi.org/10.4324/ 9780203497012

Fu, F.-L., Wu, Y.-L., \& Ho, H.-C. (2009). An investigation of coopetitive pedagogic design for knowledge creation in web-based learning. Computers \& Education, 53(3) 550-562. https://doi.org/ 10.1016/j.compedu.2009.01.004

Klymchuk, S. (2017). Puzzle-based learning in engineering mathematics: Students' attitudes. International Journal of Mathematical Education in Science and Technology, 48(7), 1106-1119. https://doi.org/10.1080/0020739X.2017.1327088

Mullins, D. R., Rummel, N., \& Spada, H. (2011). Are two heads always better than one? Differential effects of collaboration on students' computer-supported learning in mathematics. International Journal of Computer-Supported Collaborative Learning, 6(3), 421-443. https://doi.org/10.1007/s11412-011-9122-z

Palm, T. (2009). Theory of authentic task situations. In L. Verschaffel, B. Greer, \& W. Van Dooren (Eds.), Words and worlds: Modelling verbal descriptions of situations (pp. 3-17). Sense Publishers. 
Palm, T., \& Burman, L. (2004). Reality in mathematics assessment: an analysis of task-reality concordance in Finnish and Swedish national assessments. Nordic Studies in Mathematics Education, 9(3), $1-38$.

Plass, J. L., O’Keefe, P. A., Homer, B. D., Case, J., Hayward, E. O., Stein, M., \& Perlin, K. (2013). The impact of individual, competitive, and collaborative mathematics game play on learning, performance, and motivation. Journal of Educational Psychology, 105(4), 1050-1066. https://doi.org/10.1037/a0032688

Schoenfeld, A. H. (1985). Mathematical problem solving. Academic Press.
Selden, A., Selden, J., Hauk, S., \& Mason, A. (2000). Why can't calculus students access their knowledge to solve nonroutine problems? Research in Mathematics Education, IV, Issues in Mathematical Education, 8, 128-153.

Slavin, R. E. (1988). Cooperative learning and student achievement. Educational Leadership, 31-33.

Thomas, C., Badger, M., Ventura-Medina, E., \& Sangwin, C. (2013). Puzzle-based learning of mathematics in engineering. Engineering Education, 8(1), 122-134. https://doi.org/10.11120/ened.2013. 00005 


\section{APPENDIX A-December 23 ${ }^{\text {rd }}$ Evaluation}

Firefox

\section{OOeleot

Purpose: The putpose of this tool is to help you identify and document observable endence of classroom environments that are conducive to student learning. Circle the number that corresponds with your observation of each learning environment item descrictor. As needed and appropriate, make inquiries with learners.

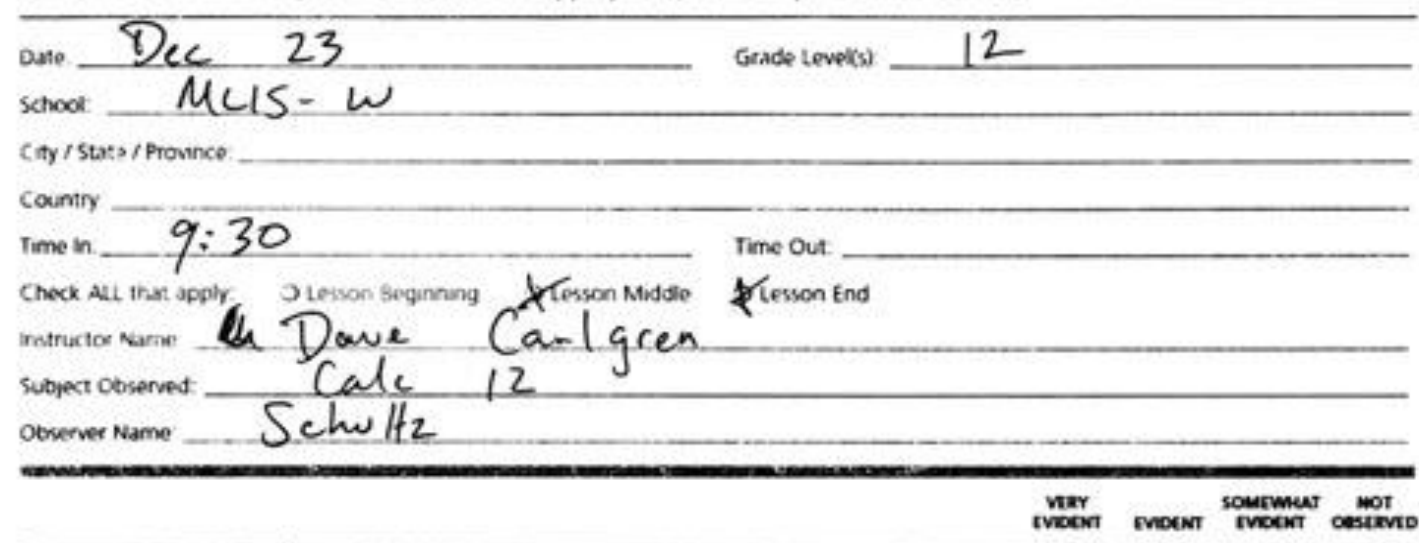

A. Eçuitable Learning Environment:

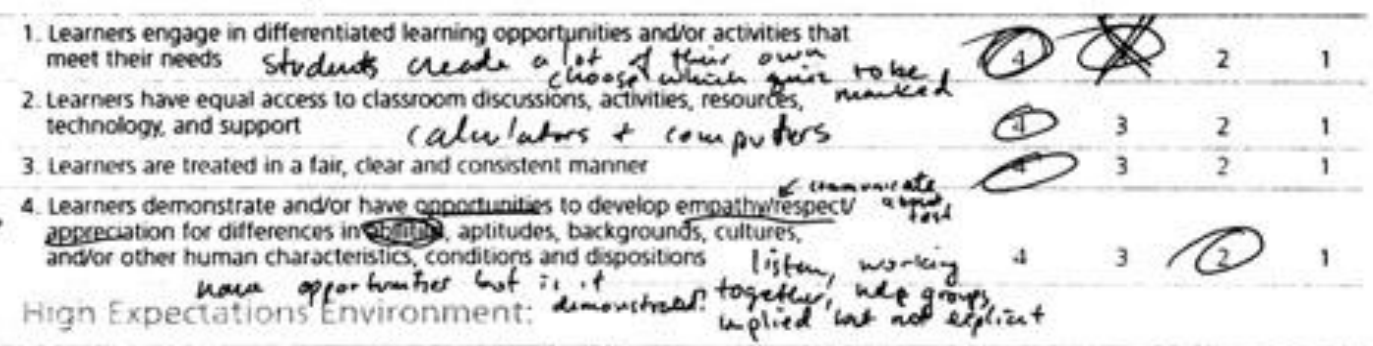

1. Learners strive to meet or are able to articulate the high expectations established by

chemseressindor the teacher we che rubnc and

2. Learners engage in activities and learning that are challenging but attainable wmering forth

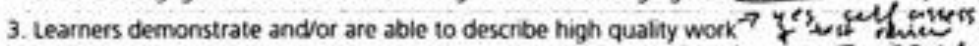

4. Learners engage in rigorous coursework, discussions, andibr tasks that require the ?jects

use of higher order thinking (e.g., analyzing. applying, evaluating. synthesizing), rubries

5. Learners take responsibility for and are self-directed in their learning

$$
\text { Eniz chice o croter thin }
$$

9115 westude Flwy. Alphantia GA 30009 p: +1888.41 ED NOWv e. contartusasdvanc.ed oeg

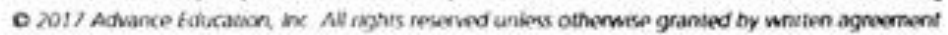


Firefox

\section{OO eleot}

\section{VERY
EVIDENT EVIDENT SOMEWHAT NOT
EVIDENT OBSERVED}

C. Supportive Learning Environment:

1. Learners demonstrate a sense of community that is positive, cohesive, engaged and purposeful

2. Learners take rişks in learning (withoyt fear of negative feegback) talleing during pres $\frac{4}{4}$

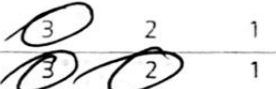

3. Learners are supported by the teacher, their peers indyor other resources to understand content and accomplish tasks help pach other, questions after 4 (4) 321 4. Learners demonstrate a congenial and supportive relationship with their teacher

D. Active Learning Environment: kisten to teaishe; no issues; listem to stop wroting on desk

studuats spola wisch the Studeut prasentation

1. Learners' discussions/dialogues/exchanges with each other and the teacher predominate 2. Learners make connections from content to real-life experiences - game? (Tifunic) 3. Learners are actively engaged in the learning activities souriz/rest/ol hur

4. Learners collaborate with their peers to accomplish/complete projects, activities, tasks andror assignments sthe clearly yes, sone seen

${ }_{4}^{4} \begin{array}{lll}3 & 2 & 1 \\ 3 & 2 & 1 \\ 3 & 2 & 1\end{array}$
(4) 21

E. Progress Monitoring and Feedback Environment:

1. Learners monitor their own learning progress or have mechanisms whereby cue the ow on

2. Learners receive/respond to feedback (from teachers/peers/other resolices) others will cample to improve understanding and/or revise work $Q+A$ durmy eresentations

3. Learners demonstrate and/or verbalize understanding of the lessoncontent $\rightarrow$ culy say 4. Learners understand and/or are able to explain how their work is assessed cuate rubric will assess

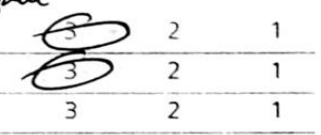

F. Well-Managed Learning Environment:

$$
\text { mostly but }
$$

. Learners speak and interact respectfully with teacher(s) and each other some coustracke

2. Learners demonstrate knowledge of and/or follow classroom rules and benavioral expectations and work well with others food in class

3. Learners transition smoothly and efficiently from one activity to another minimal tos 4. Learners use class time purposefully with minimal wasted time or disruptions

G. Digital Learning Environment: Majomby op task peview y/working a fur on phones/ipad in a seeming

1. Learners use digital tools/technology to sam resylt bit miving it some checking (awas - but.

2. Learners use digital tools/technology to conduct research, solve problems, and/or this cowse create original works for learning calc or guiz

3. Learners use digital tools/technology to communicate and/or work collaboratively for learning soint sonething on calc? but didrit show how to use calc to git
vesuftes as necessary)

Notes (Attach another sheet for notes as necessary) 


\section{APPENDIX B-December 24th Evaluation}

ruretox

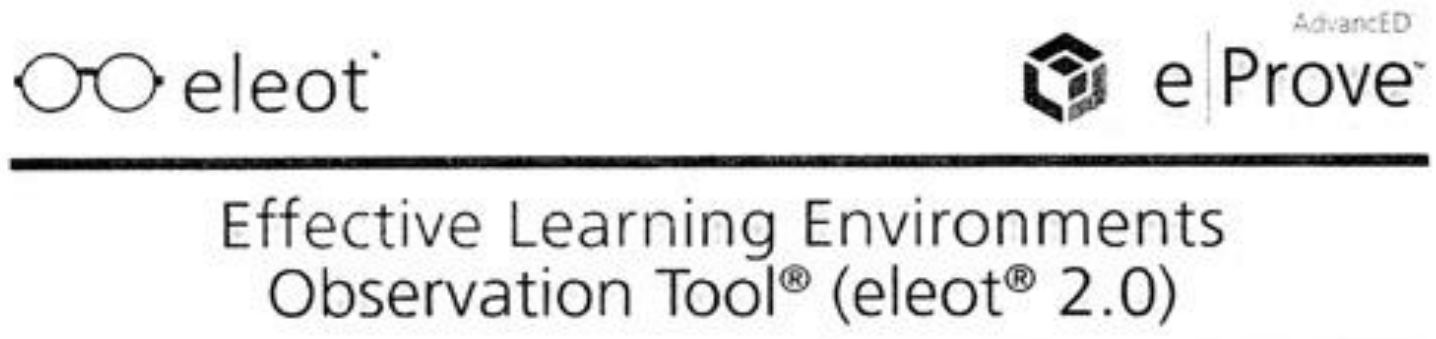

Purpose: The purpose of this tool is to help you identify and document observable evidence of classroom environments that are conducive to student learning. Circle the number that corresponds with your observation of each learning environment item descriptor. As needed and approptiate, make inquities with learners.

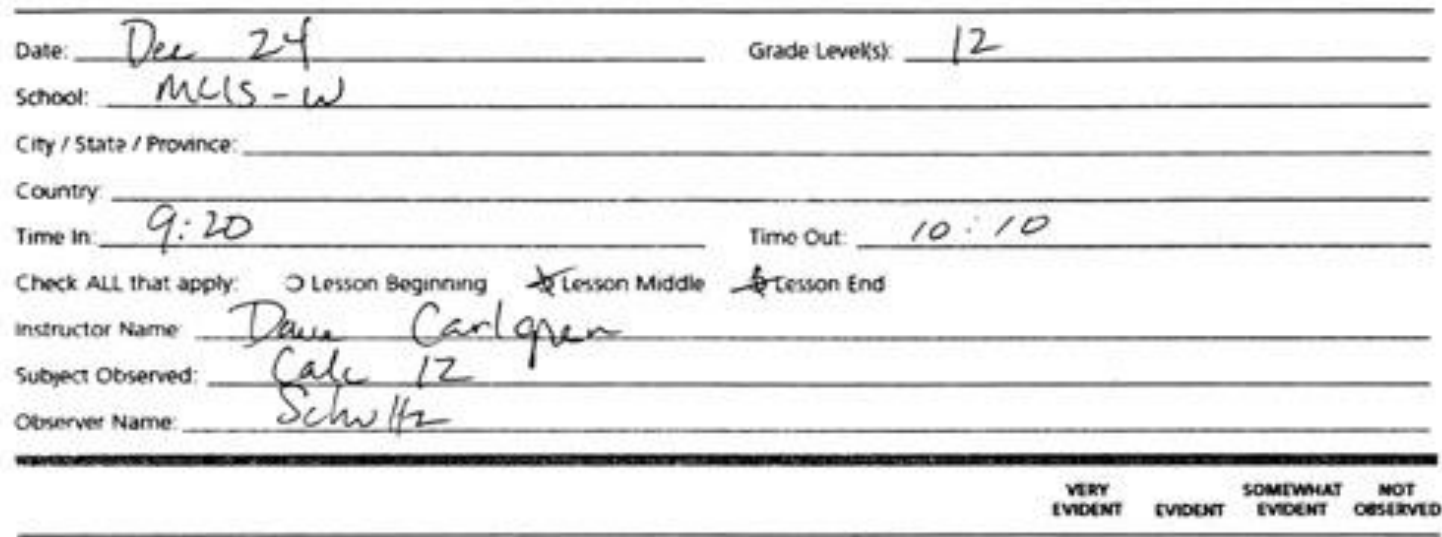

A. Equitable Learning Environment:

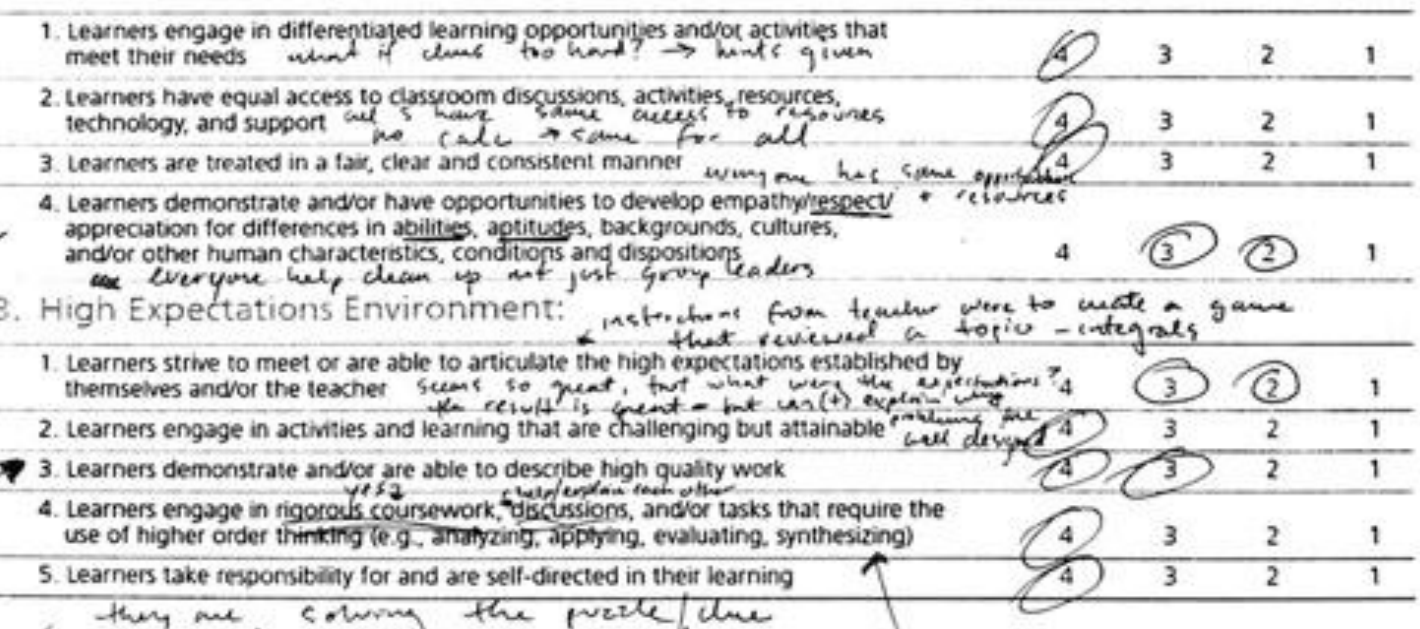

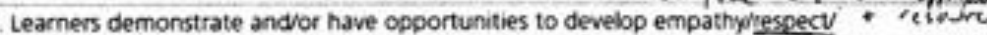
ppreciation for differences in abilities, aptitudes, backgrounds, cultures, andor other human characteristics, conditions and dispositions gader

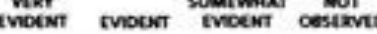

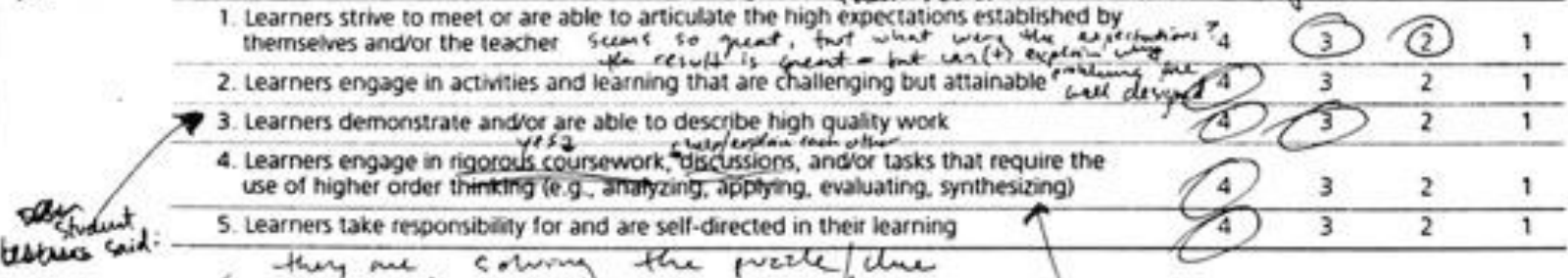

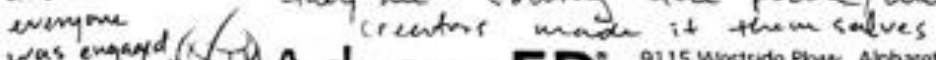

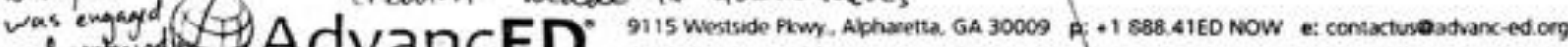
and parphancED and exjoying

6 its an gleat

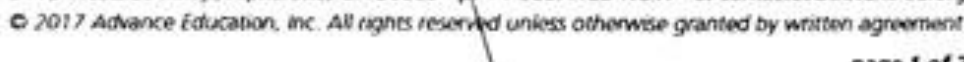

activity ort

if the point.

if rwion doss

it $d$. thed will?

mww. advenced.org

rraditancal and accorden to sfodent more visefil review given later 
irefox

\section{OO eleot

VERY
EVIDENT EVIDENT SOMEWHAT NOT
EVIDENT OBSERVED

C. Supportive Learning Environment:

1. Learners demonstrate a sense of community that is positive, cohesive, engaged,

2. Learners take risks in learning (without fear of negative feedback) lup trying to find $40 \begin{array}{llll}3 & 2 \\ 3 & 2\end{array}$

3. Learners are supported by the teacher, their peers and/or other resources to
understand content and accomplish tasks clues in ths le lup emh othr
4. Learners demonstrate a congenial and supportive relationship with their teacher

4. Learners demonstrate a congenial and supportive relationship with their teacher

D. Active Learning Environment:

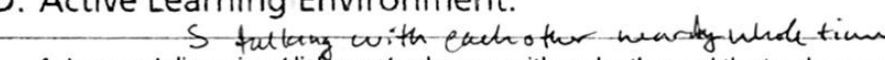

1. Learners' discussions/dialogues/exchanges with each other and the teacher predominate $\begin{array}{lllll}4 & 3 & 2\end{array}$

2. Learners make connections from content to real-life experiences pvizles of muth 32

3. Learners are actively engaged in the learning activities evempone fring to solve 4

4. Learners collaborate with their peers to accomplish/complete projects, activities, tasks and/or assignments eveyoue movking on solving pural

E. Progress Monitoring and Feedback Environment:

10

1. Learners monitor their own learning progress or have mechanisms whereby $/ p$ / clues

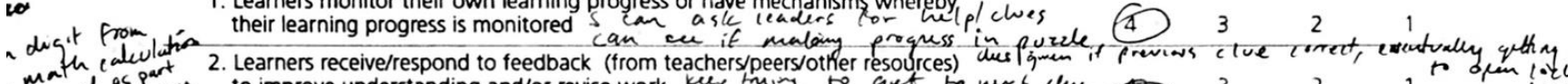

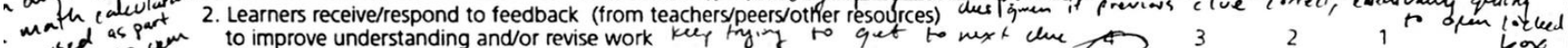

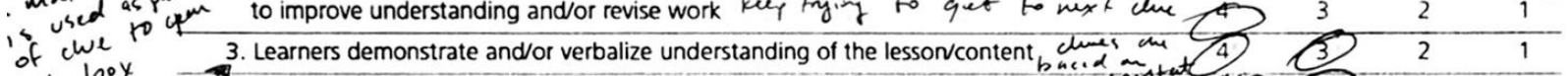

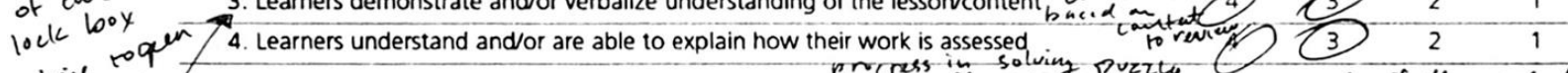

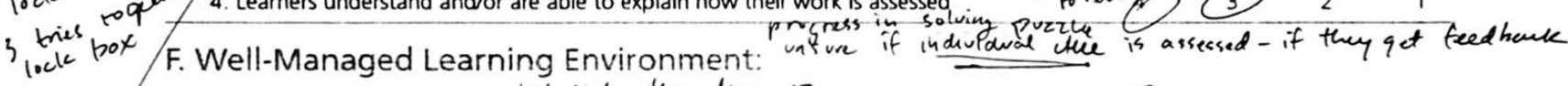

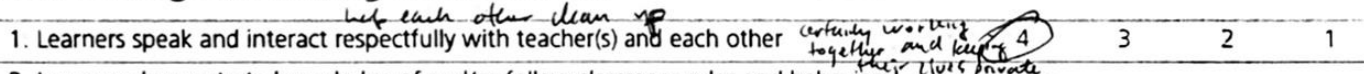

2. Learners demonstrate knowledge of and/or follow classroom rules and behavioral clues sn

expectations and work well with others Clean + urganize clase ofter

3. Learners transition smoothly and efficiently from one activity to another puzzle, clean,

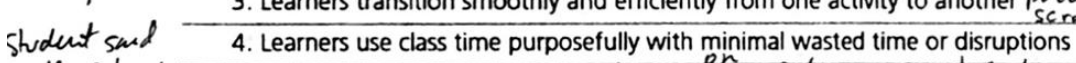

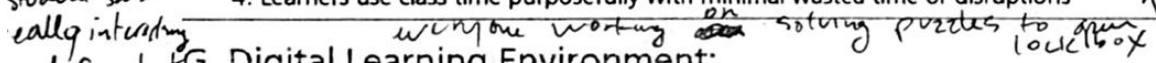

and fun butG. Digital Learning Environment:

not very use fot 1. Learners use digital tools/technology to gather, evaluate, and/or use information

for review for learning tech restricted by organieurs of projed

2. Learners use digital tools/technology to conduct research, solve problems, and/or create original works for learning

3. Learners use digital tools/technology to communicate and/or work collaboratively for learning

$\begin{array}{llll}3 & 3 & 2 & 1 \\ 4 & 3 & 2 & 1 \\ 4 & 2 & 1\end{array}$

Notes (Attach another sheet for notes as necessary)

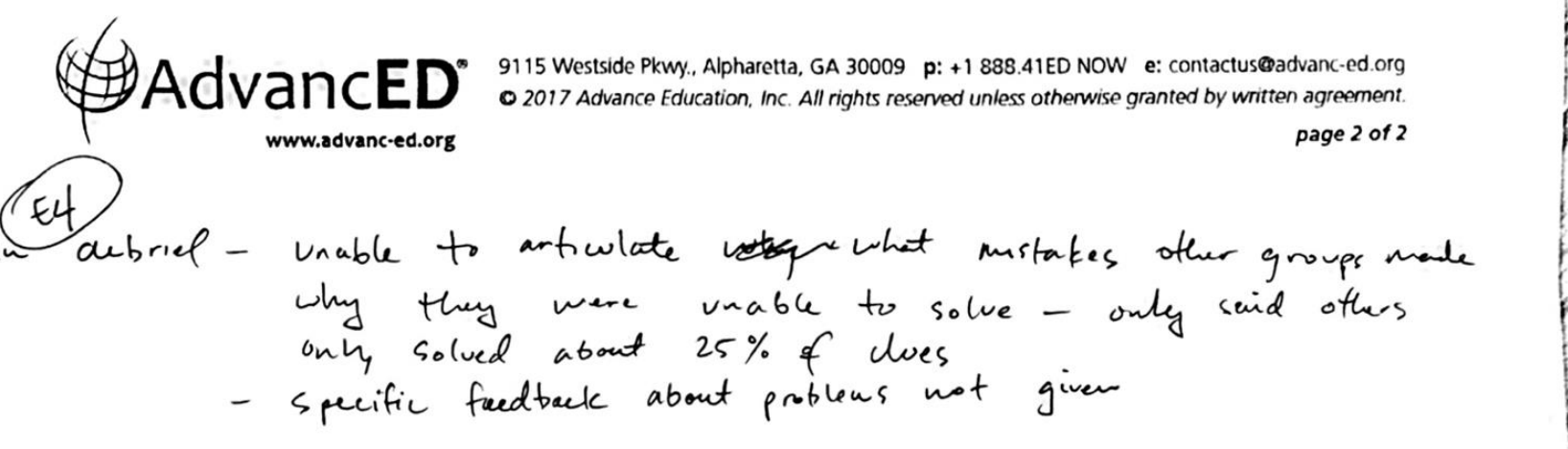

slow to mave to partmers

$4 \quad 3 \quad 2$

$\begin{array}{llll}4 & 3 & 2 & \end{array}$

32




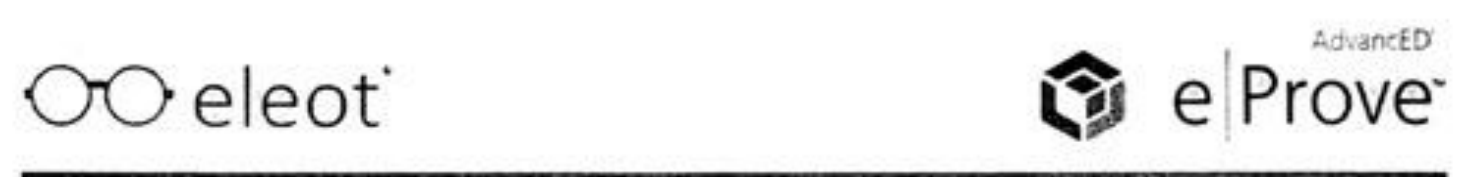

\section{Effective Learning Environments Observation Tool $^{\circledast}\left(\right.$ eleot $\left.^{\circledR} 2.0\right)$}

Purpose: The purpose of this tool is to help you identify and document observable evidence of classroom environments that are conducive to student learning. Circle the number that cotresponds with your observation of each learning environment item descriptor. As needed and appropriate, make inquiries with learners.

Date: $12 / 28 \quad$ Grade Level(s): 12

ctry/state/Province:

Time in: $9: 15$

Check All that apply: Otesson Beginning OLesson Middle OLesson End

instructor Name Cadgren

subpect observed: $\mathrm{Calc}_{\mathrm{C}} \mathrm{C}^{2}$

obsenver Name. Selw/tz

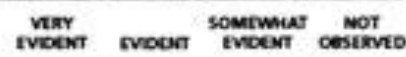

A. Equitable Learning Environment:

1. Learners engage in differentiated learning opportunities and/or activites that meet their needs Difforat lavel of quosfims - but gath

2. Learners have equal access to classtoom discussions, actinties, resourthes. technology, and support

3. Learners are treated in a fair, clear and consistent manner

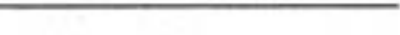

with group 4. Learners demonstrate andvor have opportunities to develop empathyrespect
appreciation for differences in abilities, aptitudes, backgrounds, cultures,

1. Learners strive to meet or are able to articulate the high expectations established by
andreciation for ditterences in abilities, aptitudes, backgrounds, cultures, certanaly had high

expectations and performed lavel

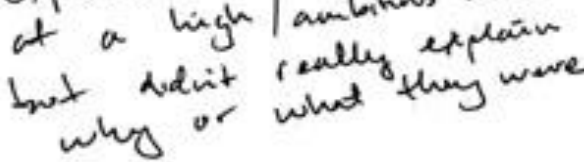


irefox

\begin{tabular}{l} 
VERY \\
EVIDENT EVIDENT SOMEWHAT NOT \\
EVIDENT OBSERVED \\
\hline
\end{tabular}

\section{Supportive Learning Environment:}

\begin{tabular}{|c|c|c|c|c|}
\hline $\begin{array}{l}\text { 1. Learners demonstrate a sense of community that is positive, cohesive, engaged, } \\
\text { and purposeful workeng together }\end{array}$ & (4) & 3 & 2 & 1 \\
\hline 2. Learners take risks in learning (without fear of negative feedback) Apumshnentit but & (5) & 3 & 2 & 1 \\
\hline $\begin{array}{l}\text { 3. Learners are supported by the teacher, their peers and/or other resources to } \\
\text { understand content and accomplish tasks working in groups }\end{array}$ & (4) & 3 & 2 & 1 \\
\hline 4. Learners demonstrate a congenial and supportive relationship with their teacher & 4 & 3 & 2 & 1 \\
\hline
\end{tabular}

sheent D. Active Learning Environment: about game, but content?

sheent D. Active Learning Environment: Bowt game, but, ontent?

veadunted ims 1. Learners' (iscussions/dialogues/exchanges with each other and the teacher predominate 4 (4) 2 (3) 1

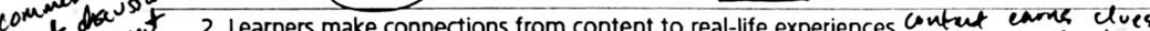

that $\mathrm{g}^{\mathrm{u}} \mathrm{s}$ 2. Learners make connections from content to real-life experiences that cen rest to to

were whe 3. Learners are actively engaged in the learning activities

es e iu $q^{\text {se }}$ 4. Learners collaborate with their peers to accomplistvcomplete projects, activities, tasks and/or assignments

$$
\text { ceate the gane, wark to vir the gaure }
$$

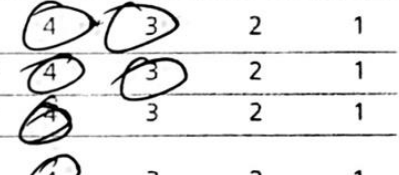

E. Progress Monitoring and Feedback Environment:

ineate thir own rubric that teuber will use to make it
1. Learners monitor their own learning progress or have mechanisms whereby

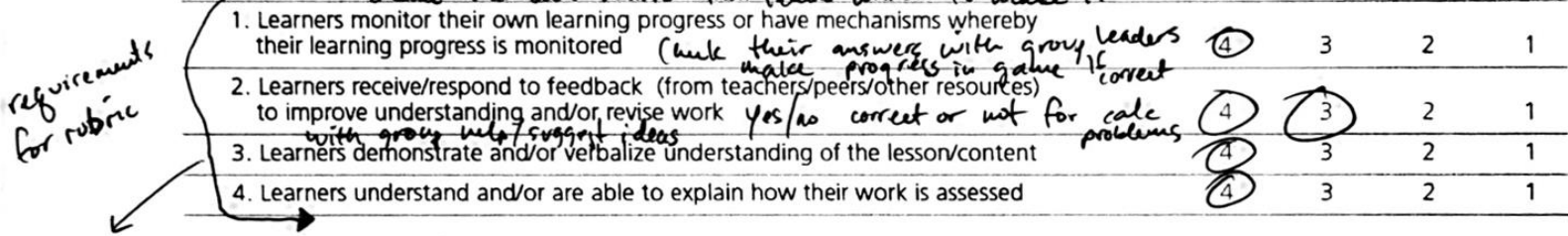

F. Well-Managed Learning Environment:

answer

$7-10$

1. Learners speak and interact respectfully with teacher(s) and each other

behavioral

2. Learners demonstrate knowledge of and/or follow classroom rules and
expectations and work well with others Clive colkm

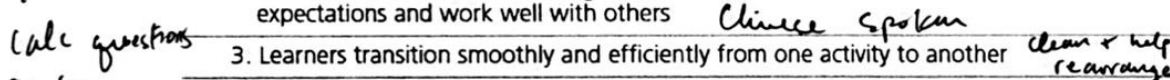

in this 4 . Learners use class time purposefully with minimal wasted time or disruptions

\section{class \\ G. Digital Learning Environment: \\ perp}

\begin{tabular}{|c|c|c|c|c|}
\hline $\begin{array}{l}\text { 1. Learners use digital tools/technology to gather, evaluate, and/or use information } \\
\text { for learning Use calculators }\end{array}$ & (4) & 3 & 2 & 1 \\
\hline $\begin{array}{l}\text { 2. Learners use digital tools/technology to conduct research, solve problems, and/or } \\
\text { create original works for learning crecte the gque (nothast this }\end{array}$ & 4 & & 2 & 1 \\
\hline $\begin{array}{l}\text { 3. Learners use digital tools/technology to communicate and/or work collaboratively } \\
\text { for learning compare graphs an desmes nof all tho }\end{array}$ & 4 & & 2 & 1 \\
\hline
\end{tabular}

Notes (Attach another sheet for notes as necessary)

(AdvancED

9115 Westside Pkwy. Alpharetta, GA 30009 p: +1 888.41ED NOW e: contactus@advanc-ed.org 02017 Advance Education. Inc. All rights reserved unless otherwise granted by written agreement.

$$
4 \text { another does not, says it's enjoyable but less efficent }
$$

chodent does think its useful review for thir course and final exam

2 studente prefor this game way to veview unstend of a tradituonal view

Dthis or tradiond?

(2) why so ambitious?

2 of 2

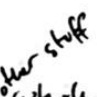

Whole cluss feedhouk from students 


\section{APPENDIX D- ELIOT 2.0 Tool}

\section{OO eleot 1. e Prove \\ Effective Learning Environments Observation Too ${ }^{\circledR}\left(\right.$ eleot $\left.^{\circledR} 2.0\right)$}

Purpose: The purpose of this tool is to help you identify and document observable evidence of classroom environments that are conducive to student learning. Circle the number that corresponds with your observation of each learning environment item descriptor. As needed and appropriate, make inquiries with learners.

Date:

Grade Level(s):

School:

City / State / Province;

Country:

Time in:

Time Out:

Check ALL that apply: O Lesson Beginning O Lesson Middle O Lesson End

Instructor Name:

Subject Observed:

Observer Name:

VERY
EVIOENT ENIDENT SOMEWHAT NOT
EVIDENT OBSERVED

\section{A. Equitable Learning Environment:}

1. Learners engage in differentiated learning opportunities and/or activities that meet their needs

$\begin{array}{lll}4 & 3 & 2\end{array}$

2. Learners have equal access to classroom discussions, activities, resources, technology, and support

3. Learners are treated in a fair, clear and consistent manner

$\begin{array}{llll}4 & 3 & 2 & 1\end{array}$

4. Learners demonstrate and/or have opportunities to develop empathy/respect/ appreciation for differences in abilities, aptitudes, backgrounds, cultures, and/or other human characteristics, conditions and dispositions

$\begin{array}{llll}4 & 3 & 2 & 1\end{array}$

\section{B. High Expectations Environment:}

1. Learners strive to meet or are able to articulate the high expectations established by themselves and/or the teacher

2. Learners engage in activities and learning that are challenging but attainable

3. Learners demonstrate and/or are able to describe high quality work

4. Learners engage in rigorous coursework, discussions, and/or tasks that require the use of higher order thinking (e.g., analyzing, applying, evaluating, synthesizing)

5. Learners take responsibility for and are self-directed in their learning

\begin{tabular}{llll}
4 & 3 & 2 & 1 \\
\hline & 3 & 2 & 1
\end{tabular}

9115 Westside Pkwy. Alpharetta, GA 30009 p: +1 888,41EO NOW e: contactusbadvanc-ed.org 6 2017 Advance Education, inc. All rights reserved unless othervise granted by witten agreement. 


\section{$00^{\circ}$ eleot}

\section{Supportive Learning Environment:}

\begin{tabular}{|c|c|c|c|c|}
\hline $\begin{array}{l}\text { 1. Learners demonstrate a sense of community that is positive, cohesive, engaged, } \\
\text { and purposeful }\end{array}$ & 4 & 3 & 2 & 1 \\
\hline 2. Learners take risks in learning (without fear of negative feedback) & 4 & 3 & 2 & 1 \\
\hline $\begin{array}{l}\text { 3. Learners are supported by the teacher, their peers and/or other resources to } \\
\text { understand content and accomplish tasks }\end{array}$ & 4 & 3 & 2 & 1 \\
\hline 4. Learners demonstrate a congenial and supportive relationship with their teacher & 4 & 3 & 2 & 1 \\
\hline
\end{tabular}

1. Learners' discussions/dialogues/exchanges with each other and the teacher predominate $\quad \begin{array}{llll}4 & 3 & 2\end{array}$

2. Learners make connections from content to real-life experiences $\quad 4 \quad 3 \quad 2 \quad 1$

3. Learners are actively engaged in the learning activities

$\begin{array}{llll}4 & 3 & 2 & 1\end{array}$

4. Learners collaborate with their peers to accomplish/complete projects, activities, tasks and/or assignments

\section{E. Progress Monitoring and Feedback Environment:}

\section{Learners monitor their own learning progress or have mechanisms whereby} their learning progress is monitored

2. Learners receive/respond to feedback (from teachers/peers/other resources) to improwe understanding and/or revise work

3. Learners demonstrate and/or verbalize understanding of the lesson/content

4. Learners understand and/or are able to explain how their work is assessed

$\begin{array}{llll}4 & 3 & 2 & 1\end{array}$

F. Well-Managed Learning Environment:

1. Learners speak and interact respectfully with teacher(s) and each other

$\begin{array}{llll}4 & 3 & 2 & 1\end{array}$

2. Learners demonstrate knowledge of and/or follow classroom rules and behavioral expectations and work well with others

3. Learners transition smoothly and efficiently from one activity to another

$\begin{array}{llll}4 & 3 & 2\end{array}$

4. Learners use class time purposefully with minimal wasted time or disruptions

$\begin{array}{llll}4 & 3 & 2 & 1\end{array}$

G. Digital Learning Environment:

\begin{tabular}{|c|c|c|c|c|}
\hline $\begin{array}{l}\text { 1. Learners use digital tools/technology to gather, evaluate, and/or use information } \\
\text { for learning }\end{array}$ & 4 & 3 & 2 & 1 \\
\hline $\begin{array}{l}\text { 2. Learners use digital tools/technology to conduct research, solve problems, and/or } \\
\text { create original works for learning }\end{array}$ & 4 & 3 & 2 & 1 \\
\hline $\begin{array}{l}\text { 3. Learners use digital tools/technology to communicate and/or work collaboratively } \\
\text { for learning }\end{array}$ & 4 & 3 & 2 & 1 \\
\hline
\end{tabular}

Notes (Attach another sheet for notes as necessary) 